\title{
Factors influencing recovery from headache after common whiplash
}

\author{
Bogdan P Radanov, Matthias Sturzenegger, Giuseppe Di Stefano, Ayesha Schnidrig, Marin Aljinovic
}

\begin{abstract}
Objective-To assess the relation between pretraumatic and trauma related headache in patients suffering from whiplash.

Design-Follow up study of patients examined a mean (SD) of $7 \cdot 4(4 \cdot 2)$ days after trauma and again at three and six months.

Setting-Patients referred from primary care. Subjects-117 patients (mean age $30 \cdot 8(9 \cdot 5)$ years.

Main outcome measures-Prevalence of trauma related headache and the predictive relation by multiple logistic regression between different somatic and psychological variables and trauma related headache at each examination.

Results-Prevalence of trauma related headache decreased from $57 \%$ to $27 \%$. History of pretraumatic headache proved a significant risk factor for presenting with trauma related headache. A significant relation between trauma related headache and the following variables was found: at seven days the initial wellbeing score, early onset of neck pain, depression scale from the personality inventory, and the initial intensity of neck pain; at three months, intensity of neck pain, and history of pretraumatic headache; and at six months neck pain, pain intensity, and history of pretraumatic headache.

Conclusions-History of pretraumatic headache significantly increases the likelihood of presenting with trauma related headache but only in combination with findings indicative of clinically important injury to the cervical spine.
\end{abstract}

\section{Introduction}

Headache is one of the most common symptoms occurring after whiplash injury to the cervical spine ${ }^{12}$ and the most prominent reason for protracted disability in injured patients. ${ }^{3}$ According to the international classification, headache after whiplash is best classified as cervicogenic (group 11.2.1) and thus related to injured structures around the cervical spine. ${ }^{3}$ Considerable controversy still exists, however, about whether cervical disease plays any part in headache syndromes. ${ }^{46}$ The incidence of headache after whiplash injury is said to decrease during the first six months after trauma. ${ }^{7}$ Factors determining recovery from this type of headache, however, have yet to be investigated in detail. Particularly relevant is the relation between a history of headache and the development of trauma related headache after whiplash injury. In addition, psychological variables, which may be important in idiopathic headache, ${ }^{89}$ should be evaluated in relation to the development and recovery from headache after whiplash.

Studies have emphasised that the first six months after whiplash injury seem crucial in the recovery from symptoms. ${ }^{210}$ Six months' follow up after whiplash should therefore clarify which factors may influence recovery from headache in this condition.

Common whiplash in this study is defined in accordance with previous reports as being a musculoligamental sprain or strain of the cervical region due to hyperflexion or hyperextension without fractures or dislocations of the cervical spine. ${ }^{11}$ Any head injury or alteration of consciousness excludes the diagnosis of common whiplash.

We assessed a non-selected cohort of patients with common whiplash. Our principal aims were, firstly, to estimate the rate of recovery from headache during the first six months after injury; secondly, to evaluate the predictive importance of pretraumatic headache in patients who suffered from headache as a result of injury; and, thirdly, to assess the relation between trauma related headache and different somatic and psychological variables.

\section{Patients and methods}

To obtain a non-selected cohort of patients with common whiplash we repeatedly distributed letters to primary care physicians and advertised this study in the Swiss Medical fournal. Physicians were asked to refer patients who had recently suffered this type of injury. At the time of referral the baseline examination was carried out. Follow up examinations were arranged three and six months later. As all patients were referred exclusively from primary care (that is, family doctors, usually general practitioners or internists) during follow up, the treatment of the patients remained the responsibility of the referring physician. According to the Swiss accident insurance system the treating physician is responsible for certifying disability that may follow injury. In the case of injury related disability patients receive a proportional amount of salary. If permanent disability is expected, which is the case when no therapeutic measure is likely to improve the patient's health, an assessment of permanent disability is carried out. This usually happens many months after injury. The system does not provide compensation for non-economic loss such as pain and suffering.

Patients were included if their injury was within the above definition, they had German as their native language, and they were aged under 56 years (because all patients underwent neuropsychological assessment in which test norms were available. In addition, all patients with injuries to other parts of the body were excluded. During the sampling period of 24 months 164 patients were consecutively referred. Twenty seven patients failed to meet the criteria and 20 further patients dropped out at follow up examinations (eight at three months and 12 at six months). Over two years in our catchment area (population about 800000 ) the number of whiplash injuries (perhaps including injuries to other parts of the body in an unknown number of patients) may be estimated to be about $205-210 .^{12}$ Our final sample $(n=117)$ included 73 women. The mean (SD) age of patients was $30.8(9.5)$ years (range 19-51 years), their mean educational attainment was $12.7(3.0)$ years, and the mean interval between trauma and baseline examination was $7 \cdot 4(4 \cdot 2)$ days. All patients suffered their injury in road traffic accidents (71 rear end collisons) and were fully covered by accident insurance.

Investigations at baseline, three months, and six months included complete physical and neurological evaluation, semistructured interviews, and self ratings of wellbeing and personality traits. In addition, con-

Correspondence to: 
TABLE I-Details of neurological findings and neck pain at baseline in patients with common whiplash injury

\begin{tabular}{lc}
\hline Finding & $\begin{array}{c}\text { No }(\%) \\
\text { of subjects }\end{array}$ \\
\hline Objective neurological signs: & \\
Restricted movement & $66(56)$ \\
Symptoms of radicular irritation & $17(15)$ \\
Symptoms or signs of radicular deficit & $17(15)$ \\
Neck pain at baseline & $108(92)$ \\
Onset of initial neck pain ${ }^{\star}:$ & $8(7)$ \\
Immediate & $46(43)$ \\
Within first hour & $15(14)$ \\
1-6 hours & $8(7)$ \\
6-24 hours & $31(29)$ \\
Within few days &
\end{tabular}

${ }^{\star}$ Median (interquartile range) $=1 \cdot 0(0 \cdot 17-24 \cdot 0)$ hours. For onset of initial headache the figures are $1 \cdot 5(0 \cdot 17-2 \cdot 40)$.

TABLE II-Intensity of neck pain and headache and psychological variables at baseline in patients with common whiplash injury

\begin{tabular}{|c|c|}
\hline Variable & $\begin{array}{c}\text { Mean (SD) score } \\
\text { (95\% confidence interval) }\end{array}$ \\
\hline Intensity of initial neck pain & $4.2(2 \cdot 1)(3.78$ to 4.52$)$ \\
\hline Intensity of initial headache & $3.0(3.0)(2.42$ to 3.52$)$ \\
\hline \multicolumn{2}{|l|}{ Psychological: } \\
\hline Nervousness ${ }^{\star}$ & $4.8(1 \cdot 7)(4 \cdot 48$ to $5 \cdot 10)$ \\
\hline Depression $^{\star}$ & $4.0(1.9)(3.67$ to 4.37$)$ \\
\hline Neuroticism $\star$ & $4.0(1.9)(3.63$ to 4.33$)$ \\
\hline Wellbeingt & $16.7(12.2)(14.51$ to 18.93$)$ \\
\hline
\end{tabular}

*Assessed by Freiburg personality inventory.

tAssessed by wellbeing scale. ${ }^{14}$

TABLE III-Details of pretraumatic headache in patients with common whiplash injury

\begin{tabular}{lc}
\hline Detail & No (\%) \\
\hline Pretraumatic headache ${ }^{\star}:$ & \\
No & $63(54)$ \\
Yes & $54(46)$ \\
Type† & \multicolumn{2}{c}{$54(100)$} \\
Migraine & $15(28)$ \\
Tension & $19(35)$ \\
Cervicogenic & $4(7)$ \\
Non-specified & $16(30)$ \\
Frequencył & \multicolumn{2}{c}{$54(100)$} \\
At least once a week & $36(67)$ \\
Less than weekly & $18(33)$ \\
\end{tabular}

$\star$ Percentages refer to whole sample $(\mathrm{n}=117)$.

tPercentages refer to number of patients who had history of pretraumatic headache $(\mathrm{n}=54)$.

ventional $x$ ray pictures of the cervical spine (anteroposterior, lateral, right and left oblique, lateral views in flexion and extension, anteroposterior view in lateral inclination, and the transoral view of the Dens) were taken at baseline in all patients.

Interviews at baseline, three months, and six months focused on subjective complaints. Furthermore, intensity of neck pain was rated by the patient on a scale from 0 (no pain) to 10 points. Various factors have been cited as possible indicators of severity of injury. We assessed the timing of the onset of neck pain or headache after trauma, considering that the earlier the onset of symptoms the more severe the injury..$^{13}$ Restriction of neck movement at baseline was suggested as an additional indicator of severity of damage. ${ }^{14}$ We also studied variables possibly influencing the occurrence of post-traumatic headache, including previous head trauma or previous whiplash

TABLE IV-Association between pretraumatic headache and trauma related headache in patients with common whiplash injury

\begin{tabular}{|c|c|c|c|c|c|}
\hline \multirow{2}{*}{$\begin{array}{l}\text { Time of } \\
\text { assessment }\end{array}$} & \multirow{2}{*}{$\begin{array}{c}\text { Presence of } \\
\text { trauma related } \\
\text { headache }\end{array}$} & \multicolumn{4}{|c|}{ Presence of pretraumatic headache } \\
\hline & & No & Yes & $\begin{array}{l}\text { No (\%) of } \\
\text { patients }\end{array}$ & $\chi^{2}, p$ Value \\
\hline Baseline & $\left\{\begin{array}{l}\text { No } \\
\text { Yes }\end{array}\right.$ & $\begin{array}{l}32 \\
31\end{array}$ & $\begin{array}{l}18 \\
36\end{array}$ & $\begin{array}{l}50(43) \\
67(57)\end{array}$ & $3.55,0.059$ \\
\hline Three months & $\left\{\begin{array}{l}\text { No } \\
\text { Yes }\end{array}\right.$ & $\begin{array}{l}48 \\
15\end{array}$ & $\begin{array}{l}28 \\
26\end{array}$ & $\begin{array}{l}76(65) \\
41(35)\end{array}$ & $7.94,0.004$ \\
\hline Six months & $\left\{\begin{array}{l}\text { No } \\
\text { Yes }\end{array}\right.$ & $\begin{array}{r}56 \\
7\end{array}$ & $\begin{array}{l}30 \\
24\end{array}$ & $\begin{array}{l}86(73) \\
31(27)\end{array}$ & $15.67,<0.0001$ \\
\hline
\end{tabular}

^Percentages refer to whole sample $(n=117)$. injury and pretraumatic headache. With respect to pretraumatic headache, which had to be serious enough to impair the patient's quality of life, information was obtained about its frequency, which was subdivided into at least weekly or less than weekly, and its type, which was coded according to the international headache classification. ${ }^{3}$

At baseline, three months, and six months we assessed the patient's wellbeing at the time of examinations with the wellbeing scale..$^{15}$ Impaired wellbeing is a facet of patients being negatively affected which might influence reported symptoms such as headache. ${ }^{16}$ We measured nervousness, depression, and neuroticism at baseline as factors possibly influencing headache ${ }^{89}$ These personality traits were assessed by using scales from the Freiburg personality inventory. ${ }^{17}$

We used the following evaluation strategies at each of the three assessments: estimation of the prevalence of headache and assessment of the predictive significance of different somatic and psychological factors for trauma related headache. For the latter, multiple logistic regression was performed by using trauma related headache as a dependent variable and the following independent variables: age, sex, mechanism of injury (rear end or other type of collision), previous head trauma or whiplash injury, type and frequency of pretraumatic headache, factors considered possible indicators of severity of injury (timing of initial neck pain, intensity of initial neck pain, timing of initial headache, restricted neck movement, and signs of radicular deficit or irritation at baseline), presence and intensity of neck pain, scores on wellbeing scale, and scores on scales from the Freiburg personality inventory (nervousness, depression, and neuroticism) at each investigation.

Statistical analysis was performed with the statistical package for the social sciences-X. ${ }^{18}$ As the statistical analysis was used with the same patients at all investigations Cochran's $Q$ test was used to analyse the rate of recovery from trauma related headache in the whole sample $(n=117)$ and in patients with or without a history of pretraumatic headache.

\section{Results}

Consistent with the definition of the injury no radiologically detectable damage was evident in any patient. Signs of radicular deficit (weakness and numbness) and radicular irritation (pain and paraesthesia) were found (table I). No patient had major persistent neurological findings, however, such as signs of radicular lesion or myelopathy. Further details of baseline examinations are shown in table II. No clearcut symptoms of vertebrobasilar insufficiency were recorded. A difference between the study group and those patients who dropped out at follow up was found only with regard to onset of initial neck pain, which in those who dropped out was shorter (MannWhitney $U=662 \cdot 0, p<0 \cdot 01$ ). No patient was involved in litigation during follow up.

Table III gives detailed data with regard to pretraumatic headache. At all investigations patients who suffered from pretraumatic headache had a higher and over time an increased probability of presenting with trauma related headache (table IV). One third of patients did not suffer from headache at any examination and only 22 patients (19\%) complained of headache at all three investigations (table V). All patients who developed headache during follow up (that is, at three and six months) had already complained of neck pain at baseline and suffered from it at follow up examinations. During follow up there was significant recovery from trauma related headache in the whole sample $(\mathrm{Q}=43.81, \mathrm{df}=2, \mathrm{p}<0.00001)$, in patients without a history of pretraumatic headache $(Q=32 \cdot 84$, 
TABLE V-Distribution of trauma related headache during follow up in patients with baseline/three months/ No (\%) of six months ${ }^{\star} \quad$ patients

No/no/no $39(33)$

Yes/no/no

No/yes/no

Yes/yes/no

Yes/yes/no

No/no/yes

Yes/no/yes

Yes/yes/yes

Yes/yes/yes

$33(28)$

$2(2)$

$12(10)$

4 (3)

« Numbers of patients at baseline hree months, and six months were 67,41 , and 31 , respectively. common whiplash injury

Presence of headache at

$\mathrm{df}=2, \quad \mathrm{p}<0.00001)$, and in those who suffered from pretraumatic headache $(Q=13 \cdot 50$, $\mathrm{df}=2, \mathrm{p}<0.002$ ).

Trauma related headache was described as arising in the occiput projecting to frontotemporal. In $16(14 \%)$ at baseline $32(21 \%)$ at three months and $35(30 \%)$ at six months this projection was unilateral. The quality of pain did not fulfil criteria of any defined neuralgia. Aggravation of trauma related headache by neck movement was reported by $87(54 \%)$ patients at baseline, $63(54 \%)$ at three months, and $62(53 \%)$ at six months.

Table VI shows factors identified by logistic regression as being significantly related to trauma related headache at each investigation.

\section{Discussion}

Our aim was to assess the rate of recovery from trauma related headache in patients with common whiplash and the predictive significance of somatic and psychological factors which may influence it. We used defined criteria of injury for screening and sampling procedures on a non-selected sample. On the basis of results from a previous retrospective study of cervical spine injuries in Switzerland ${ }^{12}$ the number of patients enrolled in our study probably reflects a representative sample of the total number of whiplash injuries in our catchment area. The investigated sample was homogeneous as all patients were injured in road traffic accidents, had similar socioeconomic backgrounds and educational attainments, and were fully covered by accident insurance. As the insurance scheme provides only for economic loss, bias due to compensation seeking behaviour is improbable. As any head injury was excluded by definition, headache after concussion as an underlying cause is excluded.

Trauma related headache decreased from $57 \%$ to $27 \%$ during follow up. Detailed analysis indicated an even higher rate of recovery as only 22 patients $(19 \%)$ suffered from it at all investigations. Thus the higher incidence of whiplash headache reported previously ${ }^{12919}$ may be related to the sample selection or failure to assess in more detail factors possibly influencing the recovery rate from headache. Patients who suffered from pretraumatic headache showed a tendency at baseline and a significantly higher probability at follow up of presenting with trauma related headache. Accordingly, predictive relations between headache before and after trauma were found at three and six months. There were many patients, however, who, although they had a history of headache, did not complain of it as a result of injury at any investigation. Moreover, there was significant recovery from trauma related headache in those with and without previous history of headache. Thus we could establish no direct one to one relations between pretraumatic and trauma related headache.

We found significant relations between headache and variables indicating more severe injury to the cervical spine (that is, neck pain and higher intensity of

TABLE VI-Variables predicting trauma related headache during follow up in patients with common whiplash injury (multiple logistic regression)

\begin{tabular}{|c|c|c|c|c|}
\hline Examination & Variable & B coefficient (SE) & $\mathrm{p}$ Value & $\begin{array}{l}\text { Sensitivity/ } \\
\text { specificity }\end{array}$ \\
\hline Baseline & $\left\{\begin{array}{l}\text { Initial neck pain intensity } \\
\text { Baseline score on depression scale } \\
\text { Baseline wellbeing score } \\
\text { Onset of initial neck pain }\end{array}\right.$ & $\begin{array}{r}0.2292(0.1191) \\
-0.3695(0.1481) \\
0.0747(0.0236) \\
-0.9496(0.2179)\end{array}$ & $\begin{array}{l}<0.05 \\
<0.01 \\
<0.001 \\
<0.0001\end{array}$ & $68 \% / 81 \%$ \\
\hline Three months & $\left\{\begin{array}{l}\text { History of pretraumatic headache } \\
\text { Neck pain intensity at three months }\end{array}\right.$ & $\begin{array}{l}1.3916(0.1200) \\
0.6260(0.5758)\end{array}$ & $\begin{array}{l}<0.02 \\
<0.0001\end{array}$ & $90 \% / 68 \%$ \\
\hline Six months & $\left\{\begin{array}{l}\text { Neck pain at six months } \\
\text { History of pretraumatic headache } \\
\text { Neck pain intensity at six months }\end{array}\right.$ & $\begin{array}{l}2.3345(0.7656) \\
2.0119(0.7372) \\
0.3866(0.1416)\end{array}$ & $\begin{array}{l}<0.001 \\
<0.007 \\
<0.007\end{array}$ & $94 \% / 72 \%$ \\
\hline
\end{tabular}

\section{Clinical implications}

- Headache is one of the most common symptoms after whiplash injury and the main reason for protracted disability in affected patients

- The relation between a history of headache and trauma related headache after whiplash may be relevant

- This study found that a history of headache before the injury significantly increased the likelihood of patients presenting with trauma related headache

- The severity of injury to the cervical spine was also important in the development of trauma related headache

- These results could lead to early identification of patients at risk and initiation of appropriate treatment

initial neck pain and of neck pain at follow up). Psychological factors were not of primary significance in the development of trauma related headache. This was particularly true with respect to personality traits. A significant relation between psychological variables (that is, score on the wellbeing and the depression scales, a negative relation being found for depression) and trauma related headache was found only at baseline. The two scores reflected the state of patients during the period close to the actual investigation. Thus the positive significant correlation of wellbeing score at baseline reflects the impaired adjustment to trauma related symptoms rather than a cause of headache.

Mechanisms of headache are still poorly understood $^{2122}$ and the role of the cervical spine is still controversial. ${ }^{46}$ History and examination in our study did not suggest any notable damage to the vertebral artery, neuralgia, or signs of cervicocranial sympathetic dysfunction. The established relation between neck pain and trauma related headache and its aggravation by neck movement favours a mechanical origin (musculoligamental strain or haemorrhage due to initial trauma). The significant relation between pretraumatic and trauma related headache found in this study may reflect an inherited reaction mode, as has been suggested previously for post-traumatic headache. ${ }^{20}$ History in the absence of significant cervical lesion, however, is not in itself a reliable predictor of post-traumatic headache, thus suggesting that trauma related factors are equally important. In view of these findings the classification of headache after whiplash injury as cervicogenic headache seems justified.

In summary, our results show that pretraumatic headache is a considerable risk factor for injury related headache in common whiplash. History of headache in the absence of notable cervical lesion is not in itself a reliable predictor of the likelihood of trauma related headache.

We thank Mr Pietro Ballinari, department of psychology, University of Berne, for help in performing statistical analysis, and $\mathrm{Dr}$ Sidney Shaw, department of internal medicine, University of Berne, for editorial assistance.

This study was supported by the Swiss National Science Foundation (project number 3.883-0.88) and the regional agency of the Swiss accident insurance company (Schweizerische Unfallversicherungsanstalt) in Berne. 1 Merskey H. Psychiatry and the cervical sprain syndrome. Can Med Assoc $\mathcal{F}$

2 Balla JI, Iansek R. Headaches arising from disorders of the cervical spine. In: 
Hopkins A, ed. Headache. Problems in diagnosis and management. London: Saunders, 1988:241-67.

3 Headache Classification Committee of the International Headache Society. Classification and diagnostic criteria for headache disorders, cranial neuralgias and facial pain. 1st ed. Cephalalgia 1988;suppl 7:8.

4 Edmeads J. The cervical spine and headache. Neurology 1988;38:1874-8.

5 Bellavance A, Belzile G, Bergeron Y, Huot J, Meloche J, Morand M. Cervical spine and headaches. Neurolog 1989:39:1269.

6 Boquet J Bois. Non $F$, Payenneville G, Leclerc D, Monnier J-C Moore N. Boquet J, Boismare F, Payenneville G, Leclerc D, Monnier J-C, Moore Lateralization of headache: possible role of an upper cervical trigger point
Cephalalgia 1989;9:15-24.

7 Maimaris C, Barnes MR, Allen MJ. "Whiplash injuries" of the neck: a retrospective study. Injury 1988;19:393-6.

8 Martin PR, Nathan PR, Milech D, van Keppel M. The relationship between headaches and mood. Behav Res Ther 1988;26:353-6.

9 Arena JG, Blanchard EB, Andrasik F. The role of affect in the etiology of chronic headache. $\mathcal{f}$ Psychosom Res 1984;28:79-86.

10 Pearce JMS, Whiplash injury: a reappraisal. $f$ Neurol Neurosurg Psychiatry 1989;52:1329-31.

11 Hirsch SA, Hirsch PJ, Hiramoto H, Weiss A. Whiplash syndrome: fact or fiction? Orthop Clin North Am 1988;19:791-5.

12 Dvorak J, Valach L, Schmid S. Cervical spine injuries in Switzerland. Orhopade 1987;16:2-12.
13 Deans GT, Magalliard JN, Kerr M, Rutherford WH. Neck sprain-a majo cause of disability following car accidents. Injury 1987;18:10-2.

14 Norris SH, Watt I. The prognosis of the neck injuries resulting from rear-end vehicle collisions. $f$ Bone foint Surg [Br] 1983;65-B:608-11.

15 Zersson von D. Self-rating scales in the evaluation of psychiatric treatment. In Helgason T, ed. Methodology in the evaluation of psychiatric treatment. Cambridge: Cambridge University Press, 1983:183-204.

16 Watson D, Pennebaker JW. Health complaints, stress, and distress: exploring the central role of negative affectivity. Psychol Rev 1989;96:234-54.

17 Fahre ed. Gortingen: Dr C J Hogrefe, 1984

ed. Gơttingen: Dr C J Hogrefe, 1984. 1990:44-70.

19 Radanov BP, Dvorak J, Valach L. Cognitive deficits in patients after soft tissue injury of the cervical spine. Spine 1992;17:127-31.

20 Kelly R. Headache after cranial trauma. In: Hopkins A, ed. Headache. Problems in diagnosis and management. London: Saunders, 1988:217-40.

21 Lance WJ. Fifty years of migraine research. Aust N Z F Med 1988;18:311-7.

22 Martin PR, Marie GV, Nathan PR. Psychophysiological mechanisms of chronic headache: investigation using pain induction and pain reduction procedures. 7 Psychosom Res 1992;36:137-48.

(Accepted 13 fuly 1993)

\title{
The fish odour syndrome: biochemical, familial, and clinical aspects
}

\author{
R Ayesh, S C Mitchell, A Zhang, R L Smith
}

\section{Abstract}

Objectives-To study the biochemical, familial, and clinical features of the fish odour syndrome among subjects with suspected body malodour.

Design-Subjects who responded to a newspaper article were screened for the fish odour syndrome by interview and biochemical tests. Families of subjects with the syndrome were tested if possible.

Setting-St Mary's Hospital, London, and some interviews at subjects' homes.

Subjects -187 subjects (28 males) with suspected body malodour, of whom 156 (19 males) underwent biochemical tests. Five families of six of the subjects with the fish odour syndrome agreed to further tests.

Main outcome measures-Amounts of trimethylamine and trimethylamine $\mathbf{N}$-oxide in urine collected over 24 hours under normal dietary conditions and for eight hours after oral challenge with $600 \mathrm{mg}$ trimethylamine.

Results-The fish odour syndrome was diagnosed in 11 subjects: the percentage of total trimethylamine excreted in their urine samples that was oxidised to trimethylamine $\mathrm{N}$-oxide was $<55 \%$ under normal dietary conditions and $<25 \%$ after oral challenge with trimethylamine (in normal subjects $>80 \%$ of trimethylamine was $\mathrm{N}$-oxidised). Parents of six of the subjects with the syndrome were tested: all showed impaired $\mathbf{N}$-oxidation of excreted trimethylamine $(<80 \%)$ after oral challenge, indicating that they were heterozygous carriers of the allele for the syndrome. The syndrome was associated with various psychosocial reactions including clinical depression.

Conclusions-The fish odour syndrome can be inherited in an autosomal recessive fashion. It should be considered as a possible causative factor in patients complaining of body malodour.

\section{Introduction}

Although problems with body malodour have received little attention, they can cause much distress and may induce a variety of psychosocial reactions. We have been studying the incidence and biochemical nature of trimethylaminuria, known as the fish odour syndrome. People with this condition secrete the volatile and malodorous aliphatic tertiary amine trimethylamine in their breath, sweat, urine, and other bodily secretions. ${ }^{1}$ This amine smells strongly of rotting fish, and the human nose can detect it at very low concentrations $(<1 \mathrm{ppm}) .^{2}$

Trimethylamine is derived from the intestinal bacterial degradation of food components such as choline and carnitine. ${ }^{3}$ This is normally oxidised to odourless trimethylamine $\mathrm{N}$-oxide, which is excreted in the urine. ${ }^{4}$ The ability to $\mathrm{N}$-oxidise trimethylamine is distributed polymorphically in the population, and people with the fish odour syndrome appear to be homozygous for an allele which determines an impaired ability to carry out the $\mathrm{N}$-oxidation reaction..$^{5-7}$ The incidence of heterozygous carriers of the allele for impaired $\mathrm{N}$-oxidation in the population seems to be of the order of $1 \%,{ }^{5}$ which suggests the possible presence of several thousand people with the fish odour syndrome. Evidence to support the view that the condition is more common than hitherto thought came from the response to an article about the syndrome that was published in the Independent on 17 July 1991. We report some of the results of the clinical and biochemical studies of the people who responded to the newspaper article.

\section{Subjects and methods}

In response to an article in the Independent, which described some of the clinical features and psychosocial consequences of the fish odour syndrome, we received 187 spontaneous letters of inquiry from people who suspected that they or their children had body malodour. One of us (RA) interviewed 112 of the subjects (15 males) at St Mary's Hospital or at their homes, while 75 subjects (13 males) answered a questionnaire to give details of their age, sex, occupation, smoking and drinking habits, marital status, medical history, history of allergies, and nature of the malodour (self recognition of the malodour, its onset and duration, factors influencing its severity, family history of malodour, and history of previous medical advice and treatment). The subjects provided urine samples collected over 24 hours under normal dietary conditions and for eight hours after an oral challenge test with $600 \mathrm{mg}$ trimethylamine. The samples were analysed for free trimethylamine and trimethylamine $\mathrm{N}$-oxide: the samples collected after the oral challenge test allowed identification of heterozygous carriers of the allele for the fish odour syndrome. ${ }^{7}$

The subjects who were found to have the fish odour syndrome underwent routine haematological tests: full 